\title{
Development of subcutaneous allergen immunotherapy (part 2): preventive aspects and innovations
}

\author{
Ludger Klimek · Randolf Brehler · Eckard Hamelmann · Matthias Kopp · Johannes Ring · Regina Treudler · \\ Thilo Jakob · Margitta Worm · Oliver Pfaar
}

Received: 12 June 2018 / Accepted: 24 September 2018 / Published online: 13 May 2019

(C) The Author(s) 2019

\begin{abstract}
Background Allergen immunotherapy with subcutaneous injection (SCIT) of the relevant allergen is the classic causal treatment method for IgE-mediated allergic respiratory disease and has already been successfully used for over 100 years.

Methods This publication is based on a selective literature search in PubMed and MEDLINE. Recent publications in German-language journals that are not available in literature databases were also analyzed. This literature search included original and review articles both in German and in English.

Results Primary, secondary and tertiary prevention characteristics have been demonstrated for SCIT; however, these require further evaluation. In combi-
\end{abstract}

nation with biologic agents, the safety, and in some cases the efficacy, of SCIT can be increased. Adjuvants seem to offer enormous development potential for SCIT. Aluminum salts, microcrystalline tyrosine (MCT), and monophosphoryl lipid A (MPL) are already used in commercial SCIT preparations. At the same time, other adjuvants are being researched, e.g., liposomes, microspheres, $\mathrm{CpG}$ motifs (C: nucleotide cytosine, p: phosphate, G: nucleotide guanine), or virus-like particles (VLPs). The therapeutic extracts themselves are also undergoing further development, for instance as recombinant allergens, hypoallergenic variants such as site-directed mutants (SDM), conformational variants, allergen fragmentation, allergen

\footnotetext{
R. Treudler

Department and Outpatient Clinic for Dermatology,

Venerology and Allergology, Leipzig University Hospital, Leipzig, Germany

Leipzig Interdisciplinary Center for Allergology (LICA), Leipzig, Germany

T. Jakob

Department of Dermatology and Allergology, Gießen and Marburg University Hospital (UKGM), Campus Gießen, Justus-Liebig University Gießen, Gießen, Germany

M. Worm

Department of Dermatology, Venereology, and Allergology, Charité-University Hospital Berlin, Campus Mitte, Berlin, Germany

Prof. Dr. O. Pfaar $(\bowtie)$

Chair/Section of Rhinology and Allergy, Department of Otorhinolaryngology, Head and Neck Surgery, University Hospital Marburg, Philipps-University Marburg, 35043 Marburg, Germany oliver@pfaar.org
} 
oligomers, deletion mutants, and hybrid allergens/ mosaic antigens.

Conclusion SCIT preparations are among the most innovative treatment options in the immunotherapy of allergic diseases. Due to the numerous immunological approaches, they will make treatment safer and more effective in the future with reduced effort.

Keywords Allergic rhinitis · Insect venom · Adjuvants in allergen immunotherapy · Hypoallergenic recombinant allergoids · Biologicals

$\begin{array}{ll}\text { Abbreviations } \\ \text { AIT } & \text { Allergen immunotherapy } \\ \text { APC } & \text { Antigen-presenting cell } \\ \text { CpG- } & \\ \text { ODN } & \text { CpG oligodeoxynucleotides } \\ \text { DCs } & \text { Dendritic cells } \\ \text { EMA } & \text { European Medicines Agency } \\ \text { IDO } & \text { Indoleamine 2,3-dioxygenase } \\ \text { IFN } & \text { Interferon } \\ \text { IL } & \text { Interleukin } \\ \text { LPS } & \text { Lipopolysaccharides } \\ \text { MCT } & \text { Microcrystalline tyrosine } \\ \text { MPL } & \text { Monophosphoryl lipid A } \\ \text { OIT } & \text { Oral immunotherapy } \\ \text { PAMP } & \text { Pathogen-associated molecular patterns } \\ \text { PEI } & \text { Paul Ehrlich Institute } \\ \text { PRR } & \text { Pattern recognition receptors } \\ \text { QoL } & \text { Quality of life } \\ \text { SCIT } & \text { Subcutaneous immunotherapy } \\ \text { SDM } & \text { Site-directed mutants } \\ \text { SIT } & \text { Specific immunotherapy } \\ \text { SLIT } & \text { Sublingual immunotherapy } \\ \text { TAV } & \text { Therapy Allergen Ordinance } \\ \text { Th1 } & \text { T-helper cell 1 (cellular immune response) } \\ \text { Th2 } & \text { T-helper cell 2 (humoral immune response) } \\ \text { TLR } & \text { Toll-like receptor } \\ \text { VLPs } & \text { Virus-like particles } \\ & \end{array}$

\section{Introduction}

Allergen-specific immunotherapy (AIT) with subcutaneous administration of allergen extracts (subcutaneous immunotherapy; SCIT) has been the standard procedure for the treatment of inhalant and insect venom allergies for over 100 years.

In addition to its efficacy and safety in the treatment of existing symptoms [1, 2], a number of primary, secondary, and tertiary preventive properties have also been demonstrated for SCIT [3, 4]. Combining biologic agents with SCIT increases the safety of the treatment. The effect of combined treatment was stronger compared to the effect of individual medications. Compared with other treatment options, SCIT is cost-effective and can save disease-related costs in the long term $[5,6]$.

Allergens or allergoids in commercial extracts in Germany are usually physically adsorbed to a car- rier, e.g., aluminum hydroxide $\left(\mathrm{Al}(\mathrm{OH})_{3}\right)$ or microcrystalline tyrosine (MCT) [4]. These not only provide the properties of a deposit, but also act as adjuvants. Aluminum salts, MCT, and monophosphoryl lipid A (MPL) are already used in commercial SCIT preparations [7]. Other adjuvants are considered to have enormous development potential, e.g., liposomes, microspheres, $\mathrm{CpG}$ motifs, and virus-like particles.

In combination with therapeutic extracts that have undergone further development, e.g., recombinant allergens, hypoallergenic variants such as site-directed mutants, conformational variants, allergen fragmentations, allergen oligomers, deletion mutants, and hybrid allergens/mosaic antigens, SCIT has enormous potential for development [8-10].

\section{Methods}

This publication is based on a selective literature search in PubMed and MEDLINE. Recent publications in German-language journals that are not available in literature databases were also analyzed. This literature search included original and review articles both in German and in English. Synonyms as well as translations into English were taken into account in the selection of suitable search terms in the German language, with Boolean operators AND, OR using truncations, and wildcards and the following selection of terms: allergic rhinitis; bronchial asthma, venom, insect venom allergy, wasp venom allergy, bee venom allergy, allergy; inhalant allergy; immunotherapy, hyposensitization; desensitization; subcutaneous immunotherapy, sublingual immunotherapy, therapeutic allergens, adjuvants, recombinant allergens, VLP.

\section{Results}

\section{Preventive aspects of SCIT (including asthma and new sensitizations)}

Prevention is a central issue in the treatment of children and adolescents in general, as well as allergic airway disease.

Controlled but open studies on individual preparations have shown that SCIT has preventive effects in addition to its efficacy on symptoms. To date, measures for secondary prevention, i.e., preventing the development of allergic rhinitis or bronchial asthma in patients already sensitized but yet asymptomatic, have only been investigated in small groups in clinical studies. For example, Szépfalusi et al. treated 31 children (aged 2-5 years) exhibiting monosensitization to mites or grasses but no previous symptoms of clinical relevance, with oral immunotherapy using the relevant allergen over 2 years, or observed them in the no-treatment placebo group over the same period. The in vitro investigations in this study population revealed significant upregulation of (blocking) allergen- 
specific immunoglobulin G (IgG) antibodies and immunomodulating interleukin (IL)-10. However, after 2 years, there was no significant difference in the clinical endpoint, i.e., the number of newly acquired allergic sensitizations, between placebo and treatment group [11]. To the authors' knowledge, a clinical study is currently conducted in the UK on the primary prevention of allergic disease using specific immunotherapy (SIT); the study has not been completed yet. It is possible that nonspecific strategies to induce immunological tolerance are more promising in terms of primary prevention.

Other secondary preventive aspects of SIT are aimed at preventing the development of new sensitizations or allergic march from allergic rhinitis to bronchial asthma. Although open studies on this are already available, there are no data from double-blind placebo-controlled (DBPC) studies. It was shown for a variety of SCIT preparations that the rate of new sensitizations under SCIT is less pronounced compared to conventional treatment [12-16].

The PAT (Prevention of Allergy Treatment) study is a ground-breaking investigation that showed that allergic march from allergic rhinitis to bronchial asthma can be slowed down with SCIT [17]. As part of this study, children with grass or birch pollen allergy (no child had bronchial asthma at the time; this was an exclusion criterion) underwent immunotherapy with the relevant allergen. At 3 years, significantly more children in the symptomatically treated group had developed bronchial asthma. The SCIT group had markedly fewer asthma symptoms or asthma diagnoses at 3 years, as well as in the 5-year follow-up (2 years after treatment completion), and even at 10 years (7 years following treatment completion). Unfortunately, this study was neither blinded nor placebo-controlled, meaning that its validity in terms of methodology has remained questionable.

A large DBPC study on SLIT using a Phleum pretense "grass tablet" was conducted over a 5-year period. The goal was to find out to what extent SLIT can prevent allergic march in children with allergic rhinitis. To this end, 812 children at 101 study centers in 11 countries were randomized. The primary endpoint was the time- - measured in days-from randomization to first asthma diagnosis (according to study protocol criteria). Secondary endpoints included the number of patients with asthma symptoms and/or medication at the end of the study, the rhinoconjunctivitis medication score in year 5 after the start of SLIT, and immunological parameters [18].

The results showed that SLIT with a "grass tablet" resulted in a significantly lower number of patients with asthma symptoms as well as used asthma medication during study duration as well as during the 3 year follow-up [18].

Although the primary endpoint was not met, the study shows that immunotherapy can prevent the development of asthma [18]. Further suitably designed studies are required to investigate whether this outcome can be similarly extrapolated to other allergens and other AIT preparations. From the authors' perspective, it is important that the secondary aspects of SIT in the prevention of asthma be evaluated in a product-specific manner. However, published works on both SCIT and SLIT give rise to speculation that effective SIT preparations can favorably affect disease course in a manner consistent with secondary prevention.

The goal of SIT's tertiary preventive properties is to slow down the progression of allergic disease and minimize treatment side effects. In this context, studies on AIT using mite extracts are interesting. In a clinical trial with children ( $n=65$ children, aged $6-17$ years) on SCIT with mite preparations, Zielen et al. showed that SCIT with a mite allergoid contributes to a significant reduction in the dose of inhaled glucocorticoids needed to control asthma. The average daily inhaled dose of fluticasone went down from 330 to $151 \mu \mathrm{g}$ in the SCIT group, and only from 290 to $206 \mu \mathrm{g}$ in the placebo group. The authors conclude from their data that SCIT is an effective option to reduce steroid use while maintaining disease control in mite-allergic children with controlled asthma [19].

In a large DBPC study, Virchow et al. investigated the effect of a SLIT mite tablet in 834 adults aged 17-83 years with partially controlled asthma under regular treatment with inhaled corticosteroids (ICS). The primary endpoint was the number of asthma exacerbations following a reduction of the ICS dose according to protocol and subsequent discontinuation of ICS. Significantly fewer asthma exacerbations were observed under mite SLIT in both dose groups investigated compared to placebo. Thus, the study demonstrates significant therapeutic success in allergic asthma among patients with partially controlled asthma; the treatment was also safe. Consequently, the results of this highly regarded study have already led to a statement on SLIT in allergic bronchial asthma caused by mites in the recently revised GINA guideline [20]: SIT is mentioned there for the first time as a treatment option for bronchial asthma [21]. A similar statement can be anticipated in the revised version of the German national treatment guideline (Deutsche Nationale Versorgungsleitlinie, NVL).

\section{Combining SCIT with biologic agents (anti-IgE: omalizumab)}

Omalizumab (Xolair ${ }^{\circledR}$, Novartis Pharma, Nürnberg, Germany) is a humanized, monoclonal anti-IgE antibody that binds circulating IgE molecules. This alters the binding of IgE antibodies on effector cells. Consequently, this prevents the release of inflammatory mediators that orchestrate the allergic inflammatory reaction. A second anti-IgE effect is that the number of IgE receptors on the effector cells decreases significantly when treated with omalizumab. Omalizumab 
is approved for the treatment of severe, therapy-resistant bronchial asthma from the age of 6 years and for the treatment of chronic idiopathic urticaria from the age of 12 years.

The idea of combining SIT with anti-IgE therapy is not a new one. The first study to investigate combination therapy of this kind was a children's study in Germany. The primary question in that particular study was whether omalizumab has an additive effect to SIT [22]. To answer this question, children and adolescents with grass and birch pollen allergy were recruited. As part of the four-arm study, patients underwent SCIT with a grass pollen or birch pollen extract and additionally received either omalizumab or placebo. This study impressively demonstrated the efficacy of omalizumab on symptom severity and medication use in children with allergic rhinoconjunctivitis. Already in the first year of therapy, a significant add-on effect to SIT was shown.

The following studies addressed the question of whether pretreatment with omalizumab leads to better tolerance of SIT, especially in the dose escalation phase. In a study on adults in 2006, Casale et al. showed that omalizumab pretreatment led to significantly fewer systemic side effects of SIT with a ragweed extract [23]. The study was designed in such a way that the maintenance therapy would be achieved within 1 day using a rush dose escalation. Omalizumab pretreatment resulted in a five-fold lower risk of developing an anaphylactic response to SIT rush dose escalation (odds ratio [OR], 0.17; $p=0.026$ ). At the same time, it was shown that combination therapy with omalizumab and SIT significantly improved symptoms during the ragweed season compared to SIT alone (0.69 vs. $0.86 ; p=0.044$ ).

Another study that included 131 grass-sensitized children and adults also showed that omalizumab significantly reduced symptom burden in patients with allergic rhinitis, as well as in patients with asthma comorbidity, compared to treatment with SIT alone [24]. This asthma patient group was also investigated by Massanari et al. [25]. The study enrolled $n=228$ patients with persistent asthma symptoms despite ICS. These patients underwent SIT (cat, dog, or house dust mite) following pretreatment with omalizumab or placebo. Significantly more patients achieved the SIT maintenance dose in the omalizumab group (110 [87.3\%] vs. 88 [72.1\%]; $p=0.004)$. Patients in that group also had significantly fewer systemic allergic reactions following SIT (17/126 [13.5\%] vs. $32 / 122[26.2 \%] ; p=0.017 ; 95 \%$ confidence interval [CI] 2.91-22.56\%).

In recent years, besides SCIT against pollen allergens, greater focus has been put on a combination of anti-IgE and SIT in food allergies, most particularly food allergies to peanut and cow milk [26-29]. A phase 1 study pretreated 11 cow milk-allergic children aged 7-17 years with omalizumab prior to performing oral immunotherapy (OIT) with milk [26].
The aim of this clinical trial was to increase the quantity of milk to $2000 \mathrm{mg}$ within $7-11$ weeks. Nine of the 11 patients met the primary endpoint and tolerated the $2000 \mathrm{mg} /$ day dose within the target time window and showed no symptoms in a DBPC food challenge (DBPCFC) with milk.

Another randomized study with cow milk-allergic patients confirmed these results [29]. A total of 57 patients aged between 7 and 32 years were recruited. OIT with milk was initiated after 4 months of omalizumab or placebo pretreatment. Oral provocation testing was performed after 28 months: $88.9 \%$ tolerated $10 \mathrm{~g}$ milk in the omalizumab group and $71.4 \%$ in the placebo group $(p=0.18)$. However, there were significant differences in terms of safety and tolerance of OIT, which were significantly better in the omalizumab group [29]. Investigations in patients with peanut allergy also confirm these results: omalizumab permitted faster and safer OIT dose escalation.

Premedication with omalizumab in patients with recurrent intolerance reactions under venom immunotherapy improved tolerance in many cases [30-35]. However, uncertainty remains regarding the necessary duration and dose of omalizumab.

In summary, pretreatment with omalizumab is able to significantly enhance AIT tolerance [36]. Thus, omalizumab pretreatment in patients with uncontrolled bronchial asthma or a clinically severe food allergy offers the possibility of a causal therapy once symptoms are under control. It can be deduced from clinical trials, as well as from a number of case series, that omalizumab significantly reduces the risk of anaphylactic reactions under AIT.

The second question that arises in addition to an improved AIT safety profile relates to the extent to which omalizumab can also enhance the efficacy of SIT. This question has not been answered yet in clinical trials. To do this, investigations over a longer observation period are required. Since IgE plays an important pathophysiological role in the interaction of the allergen/antigen with antigen-presenting cells (APC) [37], immunomodulatory effects that could be additive to conventional AIT are conceivable. However, based on the current evidence, this question remains unanswered at present.

Based on the current study situation, one can assume that temporary omalizumab treatment does not affect the treatment success of continued SIT alone.

\section{Adjuvants in SCIT}

By definition, an adjuvant is an excipient that enhances the effect of a drug without having a pharmacological effect of its own [38].

Immunology and vaccines in particular are a classic field of application for adjuvants, since they can be used to increase the immune response to a vaccine in a nonspecific manner. Delayed release is often associated with an immunogenic effect, as a result of which 
increased antibody production and an increased immune response are achieved.

This treatment concept is also used in allergology [38]. The goal of using adjuvant molecules is to enhance the immunological and thus also the clinical efficacy of AIT [38].

\section{Adjuvants in commercial preparations}

At present in Germany, adjuvants are only available in products for subcutaneous use. Adjuvants were originally developed as depot carriers designed to release the antigens bound to them in a delayed manner. The assumption was that they rendered vaccine and therapy allergens safer and more effective. It has now been shown that depot carriers also have immunostimulatory effects, particularly on antigen-presenting cells (APC) [39-43].

Aluminum salts have been used as depot adjuvants in vaccinations for almost a century and, for decades, were the only adjuvants approved for vaccines worldwide [44]. They are still the most commonly used depot adjuvants in allergen-specific SCIT [40], due mainly to the ease with which the commercial formulation is produced, their long-established use, and their acceptance by the regulatory authorities.

Aluminum's "adsorbent" properties and slower release of allergens from the depot is believed to result in greater tolerance [45]. It also improves uptake in a variety of immune cells [45]. A rapid increase in allergen-specific T-cells has been observed in clinical studies [46]. As yet, the discussion on a potential accumulation of aluminum resulting in possible neurological or immunological side effects has not prompted a reassessment of the safety of aluminum in prescription allergens for SCIT in Europe and Germany $[47,48]$. The Paul Ehrlich Institute (PEI; Langen, Germany) assesses safety-based on a maintenance dose of eight subcutaneous injections each of $0.5 \mathrm{mg}$ aluminum per year (at 6-week intervals in maintenance therapy) [49], according to a European Medical Association (EMA) recommendation-as harmless [50]. However, in 2015, the PEI set-up and financed a 3-year research program called "Develop a physiologically based toxicokinetic (PBTK) model for the risk assessment of aluminium exposition by vaccination and biomedical drugs" [51]. Understandably, the data from this program are not available yet. Lifelong immunotherapy with depot insect venom, as recommended for patients in special risk groups, is to be viewed critically.

Calcium phosphate is another mineral salt used to formulate depots for commercial SCIT products [52]. However, there are no SCIT products with calcium phosphate currently available in Germany.

Microcrystalline tyrosine (MCT) is another commercially used depot adjuvant [53].

L-tyrosine is a biodegradable amino acid able to bind antigens (allergens) and causes the delayed re- lease of allergens following subcutaneous injection [54]. Radioactively labeled and allergen-bound MCT showed a half-life of $48 \mathrm{~h}$ in animal studies and was completely removed from the injection site within 7-10 days [54]. Clinical studies have shown MCT to be safe. In preclinical studies, MCT stimulated a rise in both IgG1 (Th2) and IgG2a (Th1), but not IgE (Th2). MCT is also commercially available in combination with the toll-like receptor (TLR)-4 agonist monophosphoryl lipid A (MPL) [54-57].

MPL is one of new generation adjuvants that interact with TLRs on phagocytic, endocytic, and/or APCs. Hereby, MPL stimulates TLR4, while other TLR agonists like CpG and DNA motifs stimulate TLR9 [58]. MPL is a Th1-activating, soluble adjuvant derived from lipopolysaccharides (LPS) of the gram-negative bacterium Salmonella minnesota R595. Phosphate cleavage in the LPS creates an MPL molecule with severely attenuated toxicity, but which retains the immunostimulatory activity of the original LPS molecule [59]. LPS stimulates the immune response via pathogen-associated molecular patterns (PAMP), which are detected by specific receptors (pattern recognition receptors, PRR) on the surface of APCs [60].

PAMPs are typically produced by micro-organisms, as well as unmethylated CpG motifs, which are characteristic of bacterial DNA. Since MPL exhibits important PAMP characteristics, it is easily recognized by TLR4. SCIT with MPL showed a good switch from Th2 to Thl cells and, in combination with MCT, a strong Th1 response [61-64].

\section{Adjuvants under development}

Liposomes (e.g., hemagglutinin, lipids) and oil-inwater emulsions (e.g., squalene, sorbitan trioleate, Tween ${ }^{\circledR} 80, \alpha$-tocopherol) are adjuvants widely used in approved influenza and hepatitis A vaccinations; however, they have not been used in AIT products, yet [65].

Methylated deoxycytidine-deoxyguanosine (CpG-) oligonucleotides have been found in intracellular vesicles in phagocytes [66]. They stimulate the innate immune system towards a Thl immune response, which is also a beneficial approach in SCIT [66]. In principle, CpG-oligonucleotides can be used not only for SCIT, but also for sublingual, nasal, and intradermal administration [67].

CpG-oligodesoxynucleotides (CpG-ODN) are a class of synthetically produced single-stranded DNAoligonucleotides that contain a relatively high proportion of $\mathrm{CpG}$ motifs. CpG sequence motifs (C: nucleotide cytosine, p: phosphate, G: nucleotide guanine) are extremely rare in humans: less than $2 \%$ of dinucleotides are of the CpG type. Furthermore, cytosine occurs primarily in methylated form. In the bacterial genome and in viruses, however, $\mathrm{CpG}$ dinucleotides occur more frequently and the cytosine 
is largely unmethylated. Therefore, the innate human immune system can recognize these CpG motifs in the DNA via the toll-like receptor 9.

CpG-ODN coupled with tumor antigens have been used, for example, to stimulate the induction of specific $\mathrm{CD}^{+}$and $\mathrm{CD} 4^{+} \mathrm{T}$-cells in melanoma patients [68]. CpGs have also been successfully used as adjuvants in prophylactic vaccines [69].

Clinical trials with SCIT are already available, e.g., type-B CpG-ODNs were used with the major ragweed allergen Amb al in a phase III study [70].

Other adjuvant systems are found in vaccine preparations (e.g., AS04, GlaxoSmithKline: aluminum salt plus MPL), which are approved in a commercial vaccine against hepatitis B (Fendrix ${ }^{\circledR}$ ) and human papillomaviruses (HPV; Cervarix ${ }^{\circledR}$ ) [71], but not for AIT. The importance attached to vaccine adjuvants can be estimated by the fact that the US National Institutes of Health (NIH) promotes the development of new adjuvants with its own research program [72].

Virus-like particles (VLPs) are nanoparticles that contain no viral RNA or DNA and are therefore unable to replicate. VLPs are generally derived from capsid proteins of viruses or bacteriophages. Hepatitis B and human papillomavirus vaccines are based on VLPs and have been found to be well-tolerated, immunogenic and effective in prophylactic vaccination against infections. In addition, VLPs of the bacteriophage Qbeta ( $Q \beta$ VLPs) were investigated preclinically and clinically as carriers for antigens for a variety of vaccines against neoplastic and chronic inflammatory diseases [73]. Q $\beta$ VLPs are made up of bacteriophage capsid proteins and are the same size and shape as the original bacteriophage [74]. VLPs naturally pack bacterial RNA [74]. The protein stabilizes these nucleic acids and protects them from enzyme degradation. These Q $\beta$ VLPs can be disassembled and again reassembled in the presence of oligodeoxynucleotides (ODN; see above).

The rationale for using VLPs is the extremely strong response of the human immune system to highly repetitive structures such as those found in pathogenic micro-organisms like viruses and bacteria. Therefore, viruses and viral proteins are strong activators of the human immune system. The VLPs imitate the repetitive characteristics of virus shells. They form spontaneously during the expression of shell proteins of the viruses. In contrast to complete viruses, VLPs do not carry the entire genome of the viruses and are therefore not infectious. Typically, they are well tolerated and highly immunogenic. The antigenic determinants of the VLPs are recognized by B-cell receptors and the particles are efficiently absorbed by APCs, which present VLP epitopes as T-helper cell epitopes to major histocompatibility complex (MHC) molecules [75].
Experience with VLPs and CpG motifs in the treatment of allergic diseases

Data from early studies on CpG-ODN conjugated to ragweed allergens are promising [76, 77]. Kündig et al. published a randomized phase I study with Q $\beta$-VLPs coupled to a synthetic 16-amino acid sequence of the house dust mite allergen, Der p1 (Q $\beta$-Der p1) [78]. A rapid increase in specific IgM and IgG (particularly IgG1 and IgG3) was detected on Der p1 peptides, but not in IgE antibodies with a good overall tolerance [78].

Creticos et al. tested Amb al antigens conjugated to $\mathrm{CpG}-\mathrm{ODN}$ in 25 ragweed-allergic patients in a randomized DBPC phase II study [70]. There was no significant change in the study's primary endpoint (vascular permeability of nasal mucosa measured by the albumin level in nasal lavage fluid). However, symptomatically antibody response improved significantly, as did quality of life (QoL) parameters during first ragweed pollen season after treatment, already. This effect remained stable during the second ragweed season after therapy. Treatment was well tolerated.

Senti et al. investigated the safety and clinical efficacy of treatment with type A CpGs coupled to $Q \beta$ VLPs (QbG10) [79]. This vaccination was administered together with a standard extract of a house dust mite allergen to 20 patients in an open monocentric study. The results showed excellent treatment safety, significant symptom reduction, and a significant rise in allergen-specific IgG antibodies [79].

In a randomized, multicenter SCIT-DBPC phase II study, Klimek et al. investigated the same VLPs, loaded with type A CpG G10 (CYT003-QbG10) [80]. In contrast to the previous study, however, no allergen or allergen components were administered with the vaccine. The treatment was well tolerated, safe, and showed a significant improvement in symptom and medication scores. This was the first study in which effective subcutaneous immunotherapy without allergen was performed [81, 82].

"Nonspecific" immunotherapy can also be considered a potential therapeutic option for the treatment of allergic diseases. However, the precise mechanism for the underlying immunological effect has not been elucidated, yet. Based on various animal and in vitro studies, it can be assumed that the above-mentioned induction of a strong Th1 immune response and the production of IFN- $\gamma$ alleviate the Th2 immune response in the allergic patient in favor of a Th1 response. Furthermore, there could be a direct effect on mast cells, since these also express TLR9 [83-85]. CpGs might also affect the allergic immune response by altering the activity of indoleamine 2,3-dioxygenase (IDO), a potent enzyme in T-cell regulation [86]. The upregulation of IDO in specific dendritic cells (Dcs) via type I interferon receptors following CpG stimulation resulted in T-cell suppression [87]. This 
mechanism might be able to partially explain the antiinflammatory effects of CpGs in allergic diseases.

Microspheres are polymers that have already been successfully used in other medical disciplines [88]. These particles can serve as vectors for, e.g., immunologically active substances such as allergens, and release these in a controlled manner. However, they have not been used in clinical studies on humans, yet [41].

\section{Novel active substances for SCIT}

SCIT is the oldest form of AIT. Nevertheless, particularly interesting developments have recently been seen in this field: besides the adjuvants and immunomodulators mentioned above, these include for instance recombinant allergens and hypoallergenic antigen variants [89].

\section{Native recombinant allergens}

The major allergens in the most important sources of inhalant allergen are known and can be produced using recombinant technology, now. For SIT, this provides an elegant solution to the problem of the complex standardization of allergen extracts from natural substances, since proteins of this kind can be produced in large quantities with consistent quality. The dose can be precisely specified in micrograms $(\mu \mathrm{g})$.

Recombinantly produced molecules can also be precisely defined in terms of their physical, chemical, and immunological properties, and production can be carried out in a standardized and reproducible manner-from the same master cell bank. Furthermore, the precise dosage and composition of the molecular allergen components can be specified and thus optimized. This guarantees greater purity of the preparations, which contain only the relevant proteins and are free of contamination. This would make it possible to better observe and research the mechanisms of action during use. Tailored treatment according to individual sensitization profiles would also be conceivable, even though this approach has initially been dismissed by the European Medicines Agency (EMA).

The first clinical trials involving the administration of recombinant grass pollen, birch pollen, and cat allergen proteins in the setting of SIT with subcutaneous administration have been published:

SCIT with a mixture of five recombinant grass pollen proteins $(10 \mu \mathrm{g}$ Phl p 1, $5 \mu \mathrm{g} \mathrm{Phl} \mathrm{p2,} 10 \mu \mathrm{g} \mathrm{Phl} \mathrm{p}$ 5a, $10 \mu \mathrm{g}$ Phl p 5b, $5 \mu \mathrm{g}$ Phl p 6) resulted in a $38.5 \%$ reduction in the symptom/medication score compared to placebo and demonstrates the principle efficacy of this protein mix in a proof-of-concept study [90].

The efficacy of SCIT with recombinant and natural Bet v 1 ( $15 \mu \mathrm{g}$ each) compared to a native birch pollen extract that also contained $15 \mu \mathrm{g}$ Bet v 1 was demon- strated. There were no significant differences in the efficacy of the three preparations [91].

\section{Hypoallergenic variants of recombinant allergens}

Further improvements could be achieved by modifying wild-type allergens to hypoallergenic variants. Thus, it is hoped that the reduction of IgE binding sites will result in lower IgE reactivity, resulting in a reduced rate of side effects. Increased immunological efficacy by means of other modifications is also conceivable.

As in the production of allergoids, the three-dimensional structure of recombinant proteins can also be altered. A modified Bet v-1 molecule (folding variant) has been tested for clinical efficacy and tolerance. The subcutaneous administration of an extremely high dose $(80 \mu \mathrm{g})$ of this protein has been proved to be clinically effective and well tolerated [92].

The use of peptides containing the necessary T-cell epitopes also promises a treatment with low side effect, once the IgE epitopes responsible for side effects have been eliminated. This consideration has also been used in a SCIT approach to treating patients with cat allergy [93].

The challenges and disadvantages of recombinant DNA technology include the comparatively high development costs, the selection of the appropriate major allergen, as well as the central approval process via the EMA and the subsequent benefit assessment process. In addition, special production processes and quality-control evaluation methods need to be developed for each molecular allergen [94-97].

Once the appropriate (major) allergen has been selected, mRNA is isolated from the allergen source in the next step. Complementary DNA (cDNA) is synthesized using the enzyme reverse transcriptase [98]. Using phages cDNA ("complementary" DNA) banks can be created, which are selected with respect to the most biologically active isoforms on the basis of databases of patient sera. The relevant cDNA is then cloned in a plasmid vector and expressed in a suitable expression system. To this end, the cDNA is introduced into a suitable foreign organism via insertion in an appropriate plasmid vector. Prokaryotic bacteria (e.g., Escherichia coli) and eukaryotic yeasts (e.g., Pichia pastoris) are used as recipient organisms. Prior to selecting the system, one needs to decide which glycosylation status and what level of protein stability are desired and whether there are special structural requirements such as internal disulfide bridges. Both expression systems have their disadvantages. Bacterial expression systems lack posttranslational modification and altered codons need to be used. Yeasts such as Pichia pastoris can cause excessive hyperglycosylation.

Finally, the recombinantly produced allergen is purified using chromatography methods to remove foreign proteins and endotoxins. Quality control comprises two steps: first, the identity, purity, ho- 
mogeneity, and structure of proteins are evaluated using physicochemical characterization. Immunological characteristics such as IgE reactivity, biological activity/allergenicity or T-cell reactivity are tested afterwards. A master cell bank for a specific allergen forms the basis of working cell banks to produce clinically applicable allergens.

\section{Modifying hypoallergenic recombinant allergoids}

By modifying the isolated cDNA before inclusion in a cell bank, hypoallergenically modified variants of the wild-type allergen are created. The aim of modifications is primarily to reduce IgE activity by destroying or reducing B-cell epitopes while preserving the $\mathrm{T}$-cell epitopes required to induce T-cell tolerance. Enhancement of T-cell activation is also possible. The reduced IgE reactivity could open the possibility of administering higher allergen doses. There are two approaches: genetic engineering, which requires comprehensive knowledge of properties and structure (such as T-cell epitopes, B-cell epitopes, or 3D structure) and DNA shuffling/molecular breeding, which does not require such detailed knowledge [99-103].

Genetic engineering produces:

1. Site-directed mutants: strong IgE-binding B-cell epitopes are replaced with low-binding IgE-epitopes obtained from isoforms.

2. Conformational variants: this destroys conformational-dependent B-cell epitopes.

a)Allergen fragmentations: these cause a subsequent loss of correct folding and thus of IgE binding sites.

b)Allergen oligomers: these are produced by linking several identical copies of a gene to form homomers or linking several different genes to form heteromers.

c)Deletion mutants: with this approach, site-directed mutagenesis/deletion of short sequences directly eliminates B-cell epitopes or indirectly affects conformation.

3. Allergen hybrids/mosaic antigens: by fusing different proteins to form a hybrid molecule, the immunogenicity of weak allergens is enhanced through covalent binding, and more stable and precisely defined allergen mixtures can be produced.

Peptide immunotherapy [104, 105] uses linear peptide sequences that represent fragments of the native allergen for SCIT. Due to their shorter amino acid sequence and three-dimensional structure loss, short peptide fragments exhibit lower allergenicity. Thus, there is less probability that mast cells will be activated by cross-linking of cell-bound IgE. By contrast, the possibility for adaptive, allergen-specific T-regulatory cells to be induced with IL-10 production remains undiminished.

Contiguous overlapping peptides (COPs) were developed with the aim of reducing IgE binding while maintaining the immunomodulatory effect. This principle has been implemented to date with COPs of Bet v1, the major birch pollen allergen [106], and already investigated in phase II studies [107]. Hereby only marginal clinical effects were observed, although they were statistically significant.

Another approach is BM32, a hypoallergenic, recombinantly produced, B-cell epitope-based fusion protein [108] of the major allergen of timothy grass. This molecule has already been investigated in a phase IIa study (dose-finding trial) in an allergen exposure chamber [109]. Although the subsequent phase IIb study found no significant superiority compared to placebo in the grass pollen season, there was a number of clinically and immunologically relevant effects [110]. For this peptide the results of (pivotal) phase III studies are also outstanding.

The intradermal administration of synthetic peptide immunoregulatory epitopes (SPIRE) was highly effective in a phase 2 study on cat allergy (assessment of treatment success in an allergen exposure chamber) [111]. However, a phase 3 study failed to confirm these results. Extremely strong effects were seen in both the treatment group and the placebo group [112], with the result that this peptide is currently not undergoing further development.

A further development, so-called adjuvant-free allergen peptide hydrolysate, also aims to achieve a high immunological effect with reduced IgE reactivity, [79], which has so far been demonstrated for a short duration of therapy of only three weeks [113]. The follow-up field study with these peptides on 554 grass pollen-allergic adults showed a significant but only moderate clinical advantage in the primary endpoint, as well as marked effects in the secondary endpoints investigated [114].

Overall, peptides are believed to have high innovative potential in SIT, as already demonstrated in numerous phase II studies. Further phase III studies are needed to investigate to what extent (and for which of these approaches) they will play a role in the future [89].

\section{Summary}

Subcutaneous allergen-specific immunotherapy is the longest established form of AIT. It has undergone numerous changes and refinements in its 100-year history. In addition to the development of allergen extracts, new adjuvants are also being evaluated. At present, AIT is the only available treatment capable of inducing targeted tolerance to individual allergens, particularly in allergies to inhalant allergens [115]. AIT is superior to purely symptomatic treatment due to its disease-modifying effects, which can be reflected in the prevention of asthma and new sensitizations [116]. This aspect is important not only from a medical perspective, but also in terms of AIT's very good cost-benefit ratio in the long term [5]. There is ex- 
tensive evidence for the therapeutic efficacy of SCIT with subcutaneous allergen injections or chemically modified allergen extracts (allergoids), evidence that has been reported primarily in the relevant national and international guidelines [117-119]. When administered correctly by experienced physicians, and assuming contraindications have been considered, SCIT preparations are safe and well-tolerated. SIT is recommended in Germany from the age of 5 years. New data in children will be gathered in the coming years under the German Therapy Allergen Ordinance (Therapieallergene-Verordnung, TAV). Today, SCIT can quite rightly be considered the "classic allergen immunotherapy." Over the past decade, clinical developments were focused on sublingual preparations, mainly. Today, however, increasingly highly innovative drug developments with the subcutaneous route of administration take place again.

Acknowledgements The development of this publication was financially supported by Allergopharma, Reinbek, Germany through an independent medical writing grant. The views and opinions described in this publication do not necessarily reflect those of the grantor.

Conflict of interest L. Klimek has received research funds from the following companies: ALK-Abelló, Denmark; Allergopharma, Germany; Bionorica, Germany; Biomay, Austria; Boehringer Ingelheim, Germany; Circassia, USA; Stallergenes, France; HAL, The Netherlands; Allergy Therapeutics/Bencard, Great Britain/Germany; Hartington, Spain; Lofarma, Italy and MEDA, Sweden; MSD, USA; Novartis, Switzerland; LETI, Spain; ROXALL, Germany; GlaxoSmithKline, Great Britain; Cytos, Switzerland and Curalogic, Denmark. In addition, L. Klimek is a consultant for AllergyTherapeutics/Bencard, UK/Germany; HAL, The Netherlands; MEDA, Germany; and Boehringer Ingelheim, Germany. R. Brehler has received research funding from the following companies: Allergopharma, Bencard, and Biotech Tools, as well as Genentech, LETI, Novartis, and Circassia. He has also been a speaker for ALK-Abelló, Allergopharma, Almirall, Astra Zeneca, Bencard, the German Society for the Promotion of Dermatological Research and Training (Gesellschaft zur Förderung der Dermatologischen Forschung und Fortbildung), the German Society for Information and Organization (Gesellschaft für Information und Organisation), as well as GlaxoSmithKline, Dr. Pfleger, HAL, LETI, MedUpdate, Merck, Novartis, The Otorhinolaryngology Association (Oto-RhinoLaryngologischer Verein), Pierre Fabre, Pohl Boskamp, Stallergenes, and Thermo-Fischer. R. Brehler has worked as a consultant for: Allergopharma, Bencard, HAL, LETI, and Novartis. Eckard Hamelmann has received research funding from the German Federal Ministry of Education and Research (Bundesministerium für Bildung und Forschung, BMBF), North Rhine-Westphalia State Ministry of Research (Landesforschungsministerium Nordrhein-Westfalen) and the German Research Foundation (Deutsche Forschungsgemeinschaft, DFG). He has also given lectures and been a consultant for Allergy Therapeutics/Bencard, Great Britain/ Germany; ALK-Abelló, Denmark; Allergopharma, Germany; Boehringer Ingelheim, Germany; GlaxoSmithKline, Great Britain; HAL Allergy, The Netherlands; LETI, Spain; Lofarma, Italy; Novartis, Switzerland, and Stallergenes, France. E. Hamelmann declares that he has no competing interests. M. Kopp received fees from ALK-Abelló, Allergopharma,
LETI, and Novartis, as well as from Boehringer Ingelheim, Chiesi, GlaxoSmithKline, and Infectopharm during the period of this study. J. Ring has served on advisory boards for ALK-Abelló, Allergopharma, Bencard, HAL, and Novartis. R. Treudler states that she received fees from ALK-Abelló and LETI during the period of this study. Over and above this study, she has received fees from Sanofi Aventis and Novartis. $\mathrm{T}$. Jakob has received the following grants and funding for projects other than the work submitted here: research grants and fees from ALK-Abelló, Germany; fees and nonfinancial support from Bencard/Allergy Therapeutics, Germany; research grants, fees, and nonfinancial support from Thermo Fisher Scientific, Sweden, as well as fees from Stallergenes, Germany; research grants, fees, and nonfinancial support from Allergopharma, Germany, and research grants and fees from Novartis, Germany. T. Jakob has also received fees from Springer Nature, as well as nonfinancial support from the German Society for Allergology and Clinical Immunology (Deutsche Gesellschaft für Allergie und klinische Immunologie). M. Worm reports fees for advisory boards and lecture activities from Allergopharma GmbH \& Co. KG, ALKAbelló Arzneimittel GmbH, Meda Pharma GmbH \& Co. KG, HAL Allergie $\mathrm{GmbH}$, Stallergenes $\mathrm{GmbH}$, Bencard Allergie $\mathrm{GmbH}$, LETI Pharma GmbH, outside the submitted work. O. Pfaar reports grants and personal fees from ALK-Abelló, grants and personal fees from Allergopharma, grants and personal fees from Stallergenes Greer, grants and personal fees from HAL Allergy Holding B.V./HAL Allergie GmbH, grants and personal fees from Bencard Allergie GmbH/Allergy Therapeutics, grants and personal fees from Lofarma, grants from Biomay, grants from Nuvo, grants from Circassia, grants and personal fees from ASIT Biotech Tools S.A., grants and personal fees from Laboratorios LETI/LETI Pharma, personal fees from Novartis Pharma, personal fees from MEDA Pharma, grants and personal fees from Anergis S.A., personal fees from Mobile Chamber Experts (a GA2LEN Partner), personal fees from Pohl-Boskamp, personal fees from Indoor Biotechnologies, grants from Glaxo Smith Kline, personal fees from Astellas Pharma Global, outside the submitted work.

Open Access This article is distributed under the terms of the Creative Commons Attribution 4.0 International License (http://creativecommons.org/licenses/by/4.0/), which permits unrestricted use, distribution, and reproduction in any medium, provided you give appropriate credit to the original author(s) and the source, provide a link to the Creative Commons license, and indicate if changes were made.

\section{References}

1. Distler A, Pappelendam D. 13-year overview of serious adverse drugreactions following subcutaneous specificimmunotherapy with a chemically modified allergen preparation. Allergo J Int. 2015;24:294-302.

2. Klimek L, Fox GC, Thum-Oltmer S. SCIT with a high-dose house dust mite allergoid is well tolerated. Safety data from pooled clinical trials and more than 10 years of daily practice analyzed in different subgroups. Allergo J Int. 2018;27:131-9.

3. Brehler R, Klimek L, Vogelberg C, Werfel T, Pfaar O, Hamelmann E. Evidence vs. efficacy in allergen-specific immunotherapy: considerations using the example of tradable products in Germany. Allergo J Int. 2016;25:38-43.

4. PfaarO, BachertC, BufeA, BuhlR, EbnerC,EngP, etal. Guideline on allergen-specific immunotherapy in IgE-mediated allergicdiseases: S2kGuideline of the GermanSocietyforAl- 
lergology and Clinical Immunology (DGAKI), the Society for Pediatric Allergy and Environmental Medicine (GPA), the Medical Association of German Allergologists (AeDA), the Austrian Society for Allergy and Immunology (ÖGAI), the Swiss Society for Allergy and Immunology (SGAI), the German Society of Dermatology (DDG), the German Society of Oto-Rhino-Laryngology, Head and NeckSurgery (DGHNOKHC), the German Society of Pediatrics and Adolescent Medicine (DGKJ), the Society for Pediatric Pneumology (GPP), the German Respiratory Society (DGP), the German Association of ENT Surgeons (BV-HNO), the Professional Federation of Paediatricians and Youth Doctors (BVKJ), the Federal Association of Pulmonologists (BDP) and the German Dermatologists Association (BVDD). Allergo J Int. 2014;23:282-319.

5. Klimek L, Chaker AM, Mösges R. Costs of allergic diseases and saving potential by allergenspecific immunotherapy: a personal assessment. HNO. 2017;65:801-10.

6. Reinhold T, Brüggenjürgen B. Cost-effectiveness of grass pollen SCIT compared with SLIT and symptomatic treatment. Allergo J Int. 2017;26:7-15.

7. Rabe U, Altengarten J, Benke E, Erdmann A, Erdmann AP, Fiedler G, et al. Long-term efficacy of specific subcutaneous, short-term MPL adjuvant immunotherapy over three treatment and three follow-up years, as measured by quality of life. Allergo J Int. 2017;26:147-54.

8. Klimek L, Kündig T, Kramer M, Guethoff S, Jensen-Jarolim E, Schmidt-Weber C, et al. Virus-like particles (VLP) in prophylaxis and immunotherapy of allergic diseases. Allergo J Int. 2018; https://doi.org/10.1007/s40629-0180074-y.

9. Nandy A, Häfner D, Klysner S. Recombinant allergens in specific immunotherapy. Allergo J Int. 2015;24:143-51.

10. Tonti E, Larché M. Concepts and perspectives on peptide-based immunotherapy in allergy. Allergo J Int. 2016;25:144-53.

11. Szépfalusi Z, Bannert C, Ronceray L, Mayer E, Hassler M, WissmannE, etal. Preventivesublingualimmunotherapyin preschool children: first evidence for safety and pro-tolerogenic effects. Pediatr Allergy Immunol. 2014;25:788-95.

12. Des Roches A, Paradis L, Menardo JL, Bouges S, Daurés JP, Bousquet J. Immunotherapy with a standardized Dermatophagoides pteronyssinus extract. VI. Specific immunotherapy prevents the onset of new sensitizations in children. JAllergy Clin Immunol. 1997;99:450-3.

13. Eng PA, Reinhold M, Gnehm HP. Long-term efficacy of preseasonal grass pollen immunotherapy in children. Allergy. 2002;57:306-12.

14. MöllerC,DreborgS, FerdousiHA,HalkenS, HøstA, Jacobsen $\mathrm{L}$, et al. Pollen immunotherapy reduces the development of asthma in children with seasonal rhinoconjunctivitis (the PAT-study). JAllergy Clin Immunol. 2002;109:251-6.

15. Pajno GB, Barberio G, De Luca F, Morabito L, Parmiani $\mathrm{S}$. Prevention of new sensitizations in asthmatic children monosensitized to house dust mite by specific immunotherapy. A six-year followup study. Clin Exp Allergy. 2001;31:1392-7.

16. Purello-D'Ambrosio F, Gangemi S, Merendino RA, Isola S, Puccinelli P, Parmiani S, et al. Prevention of new sensitizations in monosensitized subjects submitted to specific immunotherapy or not. A retrospective study. Clin Exp Allergy. 2001;31:1295-302.

17. Jacobsen L, Niggemann B, Dreborg S, Ferdousi HA, Halken S, Høst A, et al. Specific immunotherapy has long-term preventive effect of seasonal and perennial asthma: 10-year follow-up on thePAT study. Allergy. 2007;62:943-8.
18. Valovirta E, Petersen TH, Piotrowska T, Laursen MK, Andersen JS, Sørensen HF, et al. Results from the 5-year SQ grass sublingual immunotherapy tablet asthma prevention (GAP) trial in children with grass pollen allergy. JAllergy Clin Immunol. 2018;141:529-538.e13.

19. Zielen S, Kardos P, Madonini E. Steroid-sparing effects with allergen-specific immunotherapy in children with asthma: a randomized controlled trial. J Allergy Clin Immunol. 2010;126:942-9.

20. Virchow JC, Backer V, Kuna P, Prieto L, Nolte H, Villesen $\mathrm{HH}$, et al. Efficacy of a house dust mite sublingual allergen immunotherapy tablet in adults with allergic asthma: a randomized clinical trial. JAMA. 2016;315:1715-25.

21. Global Initiative for Asthma (GINA). Global strategy for asthma management and prevention. 2017. https://ginasthma.org/wp-content/uploads/2016/01/ wms-GINA-2017-main-report- tracked-changes-forarchive.pdf. Accessed: 03.05.2019

22. Kuehr J, Brauburger J, Zielen S, Schauer U, Kamin W, Von Berg A, et al. Efficacy of combination treatment with antiIgEplus specificimmunotherapyin polysensitized children and adolescents with seasonal allergic rhinitis. JAllergy Clin Immunol. 2002;109:274-80.

23. Casale TB, Busse WW, Kline JN, Ballas ZK, Moss MH, Townley RG, et al. Immune tolerance network group. Omalizumab pretreatment decreases acute reactions after rush immunotherapy for ragweed-induced seasonal allergic rhinitis. JAllergy Clin Immunol. 2006;117:134-40.

24. Kopp MV, Hamelmann E, Zielen S, Kamin W, Bergmann KC, Sieder C, et al. DUAL study group. Combination of omalizumaband specificimmunotherapyis superior to immunotherapy in patients with seasonal allergic rhinoconjunctivitis and co-morbid seasonal allergic asthma. Clin Exp Allergy. 2009;39:271-9.

25. Massanari M, Nelson H, CasaleT, Busse W, KianifardF, Geba GP, et al. Effect of pretreatment with omalizumab on the tolerability of specific immunotherapy in allergic asthma. JAllergy Clin Immunol. 2010;125:383-9.

26. Nadeau KC, Schneider LC, Hoyte L, Borras I, Umetsu DT. Rapid oral desensitization in combination with omalizumab therapy in patients with cow's milk allergy. JAllergy Clin Immunol. 2011;127:1622-4.

27. Sampson HA, Leung DY, Burks AW, Lack G, Bahna SL, Jones $\mathrm{SM}$, et al. A phase II, randomized, double-blind, parallelgroup, placebo-controlled oral food challenge trial of Xolair (omalizumab) in peanut allergy. J Allergy Clin Immunol. 2011;127:1309-1310.e1.

28. Schneider LC, Rachid R, LeBovidge J, Blood E, Mittal M, Umetsu DT. A pilot study of omalizumab to facilitate rapid oral desensitization in high-risk peanut-allergic patients. J Allergy Clin Immunol. 2013;132:1368-74.

29. Wood RA, Kim JS, Lindblad R, Nadeau K, Henning AK, Dawson P, et al. A randomized, double-blind, placebocontrolled study of omalizumab combined with oral immunotherapy for the treatment of cow's milk allergy. J Allergy Clin Immunol. 2016;137:1103-1110.e11.

30. Boni E, Incorvaia C, Mauro M. Dose-dependence of protection from systemic reactions to venom immunotherapy by omalizumab. Clin Mol Allergy. 2016;14:14.

31. Dantzer JA, Wood RA. The use of omalizumab in allergen immunotherapy. Clin Exp Allergy. 2018;48:232-40.

32. Omalizumab RL. A useful tool for inducing tolerance to bee venom immunotherapy. Int J Immunopathol Pharmacol. 2016;29:726-8.

33. Stretz E, Oppel EM, Räwer HC, Chatelain R, Mastnik S, Przybilla B, et al. Overcoming severe adverse reactions to venom immunotherapy using anti-IgE antibodies in 
combination with a high maintenance dose. Clin Exp Allergy. 2017;47:1631-9.

34. Wieczorek D, Kapp A, Wedi B. Intolerance of specific immunotherapy with Hymenoptera venom: jumping the hurdle with omalizumab. Hautarzt. 2014;65:791-5.

35. Yılmaz İ, Bahçecioğlu SN, Türk M. Combination of omalizumab and bee venom immunotherapy: does it work? Asia PacAllergy. 2018;8:e2.

36. Larenas-Linnemann D, Wahn U, Kopp M. Use of omalizumab to improve desensitization safety in allergen immunotherapy. J Allergy Clin Immunol. 2014;133(e2):937-937.

37. van der Heijden FL, van Neerven RJ, Kapsenberg ML. Relationship between facilitated allergen presentation and the presence of allergen-specific IgE in serum of atopic patients. Clin Exp Immunol. 1995;99:289-93.

38. Klimek L, Schmidt-Weber CB, Kramer MF, Skinner MA, Heath MD. Clinical use of adjuvants in allergen-immunotherapy. Expert Rev Clin Immunol. 2017;13:599-610.

39. BrewerJM, Conacher M, SatoskarA, Bluethmann H, Alexander J. In interleukin-4-deficient mice, alum not only generates $\mathrm{T}$ helper 1 responses equivalent to freund's complete adjuvant, but continues to induce T helper 2 cytokine production. Eur J Immunol. 1996;26:2062-6.

40. Kramer MF, Heath MD. Aluminium in allergen-specific subcutaneous immunotherapy-a German perspective. Vaccine. 2014;32:4140-8.

41. Pfaar O, Cazan D, Klimek L, Larenas-Linnemann D, Calderon MA. Adjuvants for immunotherapy. Curr Opin Allergy Clin Immunol. 2012;12:648-57.

42. SokolovskaA, HemSL, HogenEschH.Activation of dendritic cells and induction of CD4(+) T cell differentiation by aluminum-containing adjuvants. Vaccine. 2007;25:4575-85.

43. Ulanova M, Tarkowski A, Hahn-Zoric M, Hanson LA. The Common vaccine adjuvant aluminum hydroxide upregulates accessory properties of human monocytes via an interleukin-4-dependent mechanism. Infect Immun. 2001;69:1151-9.

44. De Gregorio E, Tritto E, Rappuoli R. Alum adjuvanticity: unraveling a century old mystery. Eur J Immunol. 2008;38:2068-71.

45. Casale TB, Stokes JR. Immunotherapy: what lies beyond. JAllergy Clin Immunol. 2014;133:612-9. quiz 620.

46. Chaker AM, Shamji MH, Dumitru FA, Calderon MA, Scadding GW, Makatsori M, etal. Short-term subcutaneous grass pollen immunotherapy under the umbrella of anti-IL4: a randomized controlled trial. J Allergy Clin Immunol. 2016;137:452-461.e9.

47. Guimarães LE, Baker B, Perricone C, Shoenfeld Y. Vaccines, adjuvants and autoimmunity. Pharmacol Res. 2015;100:190-209.

48. Jensen-Jarolim E. Aluminium in allergies and allergen immunotherapy. World Allergy Organ J. 2015;8:7.

49. Paul-Ehrlich-Institut (PEI). Safety assessment of Aluminium in therapy allergenes. 2014. https://www.pei.de/ $\mathrm{DE} /$ arzneimittelsicherheit-vigilanz/archivsicherheitsinformationen/2014/ablage2014/2014-01-21sicherheitsbewertung-von-aluminium-in-therapieallergenen.html. Accessed: 03.05.2019

50. European Medicines Agency. CHMP Safety Working Party's response to the PDCO regarding aluminium hydroxide contained in allergen products. 2010. http:/ / www.ema.europa. eu/docs/en_GB/document_library/Scientific_guideline/ 2011/07/WC500108657.pdf. Accessed: 03.05.2019

51. Paul-Ehrlich-Institut (PEI). Abteilung Sicherheit von Arzneimitteln und Medizinprodukten - Forschung zur Identifizierung und Minimierung von Risiken biomedi- zinischer Arzneimittel. Stand 2016. http://www.pei.de/ DE/forschung/forschungsprogramm/ forschungsfoerderung/forschungsfoerderunginhalt.html. Accessed: 03.05.2019

52. Leynadier F, Banoun L, Dollois B, Terrier P, Epstein M, Guinnepain MT, et al. Immunotherapy with a calcium phosphate-adsorbed five-grass-pollen extract in seasonal rhinoconjunctivitis: a double-blind, placebo-controlled study. Clin Exp Allergy. 2001;31:988-96.

53. Bell AJ, Heath MD, Hewings SJ, Skinner MA. The adsorption of allergoids and3-O-desacyl-4'monophosphoryl lipid A (MPL $\left.{ }^{\circledR}\right)$ to microcrystalline tyrosine (MCT) in formulations for use in allergy immunotherapy. J Inorg Biochem. 2015;152:147-53.

54. Wheeler AW, Moran DM, Robins BE, Driscoll A. l-Tyrosine as an immunological adjuvant. Int Arch Allergy Appl Immunol. 1982;69:113-9.

55. Baldrick P, Richardson D, Wheeler AW. Review of L-tyrosine confirmingits safehumanuse as an adjuvant. JApplToxicol. 2002;22:333-44.

56. DuBuske LM, FrewAJ, HorakF, Keith PK, Corrigan CJ, Aberer $\mathrm{W}$, et al. Ultrashort-specific immunotherapy successfully treats seasonal allergic rhinoconjunctivitis to grass pollen. Allergy Asthma Proc. 2011;32:239-47.

57. Wheeler AW, Woroniecki SR. Immunological adjuvants in allergy vaccines: past, present and future. Allergol Int. 2001;50:295-301.

58. Moingeon P. Adjuvants for allergy vaccines. Hum Vaccin Immunother. 2012;8:1492-8.

59. UlrichJT, Myers KR. MonophosphoryllipidA as anadjuvant. Past experiences and new directions. Pharm Biotechnol. 1995;6:495-524.

60. Klimek L, Pfaar O, Bousquet J, Senti G, Kündig T. Allergen immunotherapy in allergic rhinitis: current use and future trends. Expert Rev Clin Immunol. 2017;13:897-906.

61. Berry AR, Wheeler AW. Composition comprising phosphatidyl serine and an antigen or allergen and the use thereof (WO 2006/059142A1).2006. https://patentimages. storage.googleapis.com/0e/1e/2c/4e85803b5995eb/ WO2006059142A1.pdf..

62. Drachenberg KJ, Wheeler AW, Stuebner P, Horak F. A welltolerated grass pollen-specific allergy vaccine containing a novel adjuvant, monophosphoryl lipid A, reduces allergic symptoms after only four preseasonal injections. Allergy. 2001;56:498-505.

63. Mothes N, Heinzkill M, Drachenberg KJ, Sperr WR, Krauth MT, Majlesi Y, et al. Allergen-specific immunotherapy with a monophosphoryl lipid A-adjuvanted vaccine: reduced seasonally boosted immunoglobulin E production and inhibition of basophil histamine release by therapy-induced blocking antibodies. Clin Exp Allergy. 2003;33:1198-208.

64. Wheeler AW, Marshall JS, Ulrich JT. A Thl-inducing adjuvant, MPL, enhances antibody profiles in experimental animals suggesting it has the potential to improve the efficacy of allergy vaccines. Int Arch Allergy Immunol. 2001;126:135-9.

65. Rappuoli R, Mandl CW, Black S, De Gregorio E. Vaccines for the twenty-first century society. Nat Rev Immunol. 2011;11:865-72.

66. Alam S, Lukawska J, Corrigan C. Adjuvants in allergy: state of the art. Curr Treat Options Allergy. 2014;1:39-47.

67. Agrawal S. Modulation of oligonucleotide CpG-mediated immune stimulation by positional modification of nucleosides. 2008. https://patentimages.storage.googleapis. $\mathrm{com} / \mathrm{fe} / \mathrm{fb} / \mathrm{bf} / 81 \mathrm{a} 77 \mathrm{fc} 4052982 / \mathrm{US7329648.pdf}$. Accessed: 03.05.2019 
68. Speiser DE, Schwarz K, Baumgaertner P, Manolova V, Devevre E, Sterry W, et al. Memory and effector CD8 T-cell responses after nanoparticle vaccination of melanoma patients. J Immunother. 2010;33:848-58.

69. Cooper CL, Davis HL, Morris ML, Efler SM, Krieg AM, Li Y, et al. Safety and immunogenicity of CPG 7909 injection as an adjuvant to Fluarix influenza vaccine. Vaccine. 2004;22:3136-43.

70. Creticos PS, Schroeder JT, Hamilton RG, Balcer-Whaley SL, Khattignavong AP, Lindblad R, et al. Immune tolerance network group. Immunotherapy with a ragweed-toll-like receptor 9 agonist vaccine for allergic rhinitis. N Engl J Med. 2006;355:1445-55.

71. Garçon N, Chomez P, Van Mechelen M. GlaxoSmithKline adjuvant systems in vaccines: concepts, achievements and perspectives. Expert RevVaccines. 2007;6:723-39.

72. Parmley S. Boosting adjuvant. SciBX. 2014. https://www. nature.com/scibx/journal/v7/n44/full/scibx.2014.1281. html. Accessed: 03.05.2019

73. Bachmann MF, Jennings GT. Vaccine delivery: a matter of size, geometry, kinetics and molecular patterns. Nat Rev Immunol. 2010;10:787-96.

74. Jennings GT, Bachmann MF. The coming of age of virus-like particle vaccines. Biol Chem. 2008;389:521-36.

75. Klimek L, Schendzielorz P, Mueller P, Saudan P, Willers J. Immunotherapy of allergic rhinitis: new therapeutic opportunities with virus-like particles filled with CpG motifs. Am J Rhinol Allergy. 2013;27:206-12.

76. Marshall JD, Abtahi S, Eiden JJ, Tuck S, Milley R, Haycock $\mathrm{F}$, et al. Immunostimulatory sequence DNA linked to the Amb a 1 allergen promotes $\mathrm{T}(\mathrm{H}) 1$ cytokine expression while downregulating $\mathrm{T}(\mathrm{H}) 2$ cytokine expression in PBMCs from human patients with ragweed allergy. J Allergy Clin Immunol. 2001;108:191-7.

77. Tighe H, Takabayashi K, Schwartz D, Van Nest G, Tuck $\mathrm{S}$, Eiden JJ, et al. Conjugation of immunostimulatory DNA to the short ragweed allergen amb a 1 enhances its immunogenicity and reduces its allergenicity. J Allergy Clin Immunol. 2000;106:124-34.

78. Kündig TM, Senti G, Schnetzler G, Wolf C, Prinz Vavricka $\mathrm{BM}$, Fulurija A, et al. Der $\mathrm{p} 1$ peptide on virus-like particles is safe and highly immunogenic in healthy adults. J Allergy Clin Immunol. 2006;117:1470-6.

79. Senti G, Johansen P, Haug S, Bull C, Gottschaller C, Müller $\mathrm{P}$, et al. Use of A-type CpG oligodeoxynucleotides as an adjuvant in allergen-specific immunotherapy in humans: a phase I/IIa clinical trial. Clin Exp Allergy. 2009;39:562-70.

80. KlimekL, Willers J, Hammann-HaenniA, Pfaar O, Stocker H, Mueller P, et al. Assessment of clinical efficacy of CYT003QbG10 in patients with allergic rhinoconjunctivitis: a phase IIb study. Clin Exp Allergy. 2011;41:1305-12.

81. Klimek L, Willers J, Schendzielorz P, Kündig TM, Senti G. Immunotherapy of allergic rhinitis without allergens?: new options for immunomodulation by vaccination with viruslike particles and CpG motifs. HNO. 2013;61:826-33.

82. Kündig TM, Klimek L, Schendzielorz P, Renner WA, Senti $\mathrm{G}$, Bachmann MF. Is the allergen really needed in allergy immunotherapy? Curr Treat Options Allergy. 2015;2:72-82.

83. Hessel EM, Chu M, Lizcano JO, Chang B, Herman N, Kell $\mathrm{SA}$, et al. Immunostimulatory oligonucleotides block allergic airway inflammation by inhibiting Th2 cell activation and IgE-mediated cytokine induction. J Exp Med. 2005;202:1563-73.

84. Jagannathan $M$, Hasturk $H$, Liang $Y$, Shin $H$, Hetzel JT, Kantarci A, et al. TLR cross-talk specifically regulates cytokine production by B cells from chronic inflammatory disease patients. J Immunol. 2009;183:7461-70.
85. Matsushima H, Yamada N, Matsue H, Shimada S. TLR3-, TLR7-, andTLR9-mediated production of proinflammatory cytokines and chemokines from murine connective tissue type skin-derived mast cells but not from bone marrowderived mast cells. J Immunol. 2004;173:531-41.

86. Kline JN. Eat dirt: CpG DNA and immunomodulation of asthma. ProcAm Thorac Soc. 2007;4:283-8.

87. Mellor AL, Baban B, Chandler PR, Manlapat A, Kahler DJ, Munn DH. Cutting edge: CpG oligonucleotides induce splenic CD19+ dendritic cells to acquire potent indoleamine 2,3-dioxygenase-dependent $\mathrm{T}$ cell regulatory functions via IFN Type 1 signaling. J Immunol. 2005;175:5601-5.

88. Pang X, Chu CC. Synthesis, characterization and biodegradation of functionalized amino acid-based poly(ester amide)s. Biomaterials. 2010;31:3745-54.

89. Pfaar O, Bonini S, Cardona V, Demoly P, Jakob T, Jutel M, et al. FASIT group. Perspectives in allergen immunotherapy: 2017 and beyond. Allergy. 2018;73(Suppl 104):5-23.

90. Jutel M, Jaeger L, Suck R, Meyer H, Fiebig H, Cromwell O. Allergen-specific immunotherapy with recombinant grass pollen allergens. JAllergy Clin Immunol. 2005;116:608-13.

91. Pauli G, Larsen TH, Rak S, Horak F, Pastorello E, Valenta R, et al. Efficacy of recombinant birch pollen vaccine for the treatment of birch-allergic rhinoconjunctivitis. J Allergy Clin Immunol. 2008;122:951-60.

92. Kettner J, Meyer H, Cromwell O, Narkus A, Jost K. Specific immunotherapy with recombinant birch pollen allergen rBet v 1-FV results of 2 years of treatment (Phase II trial). Allergy. 2007;62:262.

93. Worm M, Lee HH, Kleine-Tebbe J, Hafner RP, Laidler P, Healey D, et al. Development and preliminary clinical evaluation of a peptide immunotherapy vaccine for cat allergy. JAllergy Clin Immunol. 2011;127:89-97,97.e1-14.

94. Cromwell O, Fiebig H, Suck R, Kahlert H, Nandy A, Kettner $\mathrm{J}$, et al. Strategies for recombinant allergen vaccines and fruitful results from first clinical studies. Immunol Allergy Clin North Am. 2006;26:261-81.

95. Cromwell O, Häfner D, Nandy A. Recombinant allergens for specific immunotherapy. J Allergy Clin Immunol. 2011;127:865-72.

96. Valenta R, Linhart B, Swoboda I, Niederberger V. Recombinant allergens for allergen-specific immunotherapy: 10 years anniversary of immunotherapy with recombinant allergens. Allergy. 2011;66:775-83.

97. Valenta R, Niederberger V. Recombinant allergens for immunotherapy. JAllergy Clin Immunol. 2007;119:826-30.

98. Cromwell O, Suck R, Kahlert H, Nandy A, Weber B, Fiebig H. Transition of recombinant allergens from bench to clinical application. Methods. 2004;32:300-12.

99. Ferreira F, Wallner M, Breiteneder H, Hartl A, Thalhamer J, Ebner C. Genetic engineering of allergens: future therapeutic products. Int Arch Allergy Immunol. 2002;128:171-8.

100. Klimek L, Bachert C, Lukat KF, Pfaar O, Meyer H, Narkus A. Allergyimmunotherapywithahypoallergenicrecombinant birch pollen allergen rBet v 1-FV in a randomized controlled trial. Clin Transl Allergy 2015;5:28.

101. Klimek L, Schendzielorz P, Pinol R, Pfaar O. Specific subcutaneous immunotherapy with recombinant grass pollen allergens: first randomized dose-ranging safety study. Clin Exp Allergy. 2012;42:936-45.

102. Linhart B, Valenta R. Vaccine engineering improved by hybrid technology. Int Arch Allergy Immunol. 2004;134:324-31.

103. Schendzielorz P, Klimek L. Specific immunotherapy : clinical experiencewith recombinantmolecularmajor allergens and hypoallergenic variants. HNO. 2013;61:834-42. 
104. LarchéM,Akdis CA, Valenta R.Immunological mechanisms of allergen-specific immunotherapy. Nat Rev Immunol. 2006;6:761-71.

105. Moldaver D, Larché M. Immunotherapy with peptides. Allergy. 2011;66:784-91.

106. Pellaton C, Perrin Y, BoudousquiéC, Barbier N, Wassenberg J, Corradin G, etal. Novel birch pollen specific immunotherapyformulationbasedon contiguous overlappingpeptides. Clin Transl Allergy. 2013;3:17.

107. Spertini F, DellaCorte G, Kettner A, de Blay F, Jacobsen L, Jutel M, et al. Efficacy of 2 months of allergen-specific immunotherapy with Bet $\mathrm{v}$ 1-derived contiguous overlapping peptides in patients with allergic rhinoconjunctivitis: results of a phase IIb study. J Allergy Clin Immunol. 2016;138:162-8.

108. Focke-Tejkl M, Weber M, Niespodziana K, Neubauer A, Huber H, Henning R, et al. Development and characterization of a recombinant, hypoallergenic, peptide-based vaccine for grass pollen allergy. J Allergy Clin Immunol. 2015;135:1207-7:e1-11.

109. Zieglmayer P, Focke-Tejkl M, Schmutz R, Lemell P, Zieglmayer R, Weber M, et al. Mechanisms, safety and efficacy of a B cell epitope-based vaccine for immunotherapy of grass pollen allergy. EBioMedicine. 2016;11:43-57.

110. Niederberger V, Neubauer A, Gevaert P, Zidarn M, Worm M, Aberer W, et al. Safety and efficacy of immunotherapy with the recombinant $\mathrm{B}$-cell epitope-based grass pollen vaccine BM32. JAllergy Clin Immunol. 2018;142:497-509.e9.

111. Patel D, Couroux P, Hickey P, SalapatekAM, Laidler P, Larché $\mathrm{M}$, et al. Fel d 1-derived peptide antigen desensitization shows a persistent treatment effect 1 year after the start of dosing: a randomized, placebo-controlled study. J Allergy Clin Immunol. 2013;131:103-9.e1-7.

112. Circassia Pharmaceuticals. Circassia announces top-line results from cat allergy phase III study. 2016. https:/ / www. circassia.com/media/press-releases/circassiaannounces-top-line-results-from-cat-allergyphase-iii-study/. Accessed: 03.05.2019

113. Mösges R, Kasche EM, Raskopf E, Singh J, Sohlich L, Astvatsatourov A, et al. A randomized, double-blind, placebocontrolled, dose-finding trial with Lolium perenne peptide immunotherapy. Allergy. 2018;73:896-904.

114. Mösges R, Bachert C, Panzner P, Calderon MA, Haazen L, Pirotton S, et al. Short course of grass allergen peptides immunotherapy over 3 weeks reduces seasonal symptoms in allergic rhinoconjunctivitis with/without asthma: a randomized, multicenter, double-blind, placebo-controlled trial. Allergy. 2018;73:1842-50.

115. Akdis M, Akdis CA. Mechanisms of allergen-specific immunotherapy: multiple suppressor factors at work in immune tolerance to allergens. J Allergy Clin Immunol. 2014;133:621-31.

116. Abramson MJ, Puy RM, Weiner JM. Injection allergen immunotherapy for asthma. Cochrane Database Syst Rev. 2010; https://doi.org/10.1002/14651858.CD001186.pub2.

117. Burks AW, Calderon MA, Casale T, Cox L, Demoly P, Jutel $\mathrm{M}$, et al. Update on allergy immunotherapy: American academy of allergy, asthma \& immunology/ European academy of allergy and clinical immunology/ PRACTALL consensus report. J Allergy Clin Immunol. 2013;131:1288-1296.e3.

118. Roberts G, Pfaar O, Akdis CA, Ansotegui IJ, Durham SR, Gerth van Wijk R, et al. EAACI guidelines on allergen immunotherapy: allergic rhinoconjunctivitis. Allergy. 2018;73:765-98.

119. Sturm GJ, Varga EM, Roberts G, Mosbech H, Bilò MB, Akdis CA, et al. EAACI guidelines on allergen immunotherapy: hymenoptera venom allergy. Allergy. 2018;73:744-64. 